\title{
Catherine Magnien-Simonin, Robert du Souchey, traducteur oublié du «De divinatione» de Cicéron en 1545
}

\section{Filippo Fassina}

\section{(2) OpenEdition}

1 Journals

\section{Edizione digitale}

URL: https://journals.openedition.org/studifrancesi/21111

DOI: 10.4000/studifrancesi.21111

ISSN: 2421-5856

\section{Editore}

Rosenberg \& Sellier

\section{Edizione cartacea}

Data di pubblicazione: 1 décembre 2019

Paginazione: 564-565

ISSN: 0039-2944

\section{Notizia bibliografica digitale}

Filippo Fassina, «Catherine Magnien-Simonin, Robert du Souchey, traducteur oublié du «De divinatione» de Cicéron en 1545», Studi Francesi [Online], 189 (LXIII | III) | 2019, online dal 01 mars 2020, consultato il 11 novembre 2021. URL: http://journals.openedition.org/studifrancesi/21111 ; DOI: https://doi.org/ 10.4000/studifrancesi.21111

Questo documento è stato generato automaticamente il 11 novembre 2021.

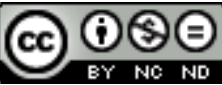

Studi Francesi è distribuita con Licenza Creative Commons Attribuzione - Non commerciale - Non opere derivate 4.0 Internazionale. 


\title{
Catherine Magnien-Simonin, Robert du Souchey, traducteur oublié $d u$ «De divinatione» de Cicéron en 1545
}

\author{
Filippo Fassina
}

\section{NOTIZIA}

Catherine Magnien-Simonin, Robert du Souchey, traducteur oublié du «De divinatione» de Cicéron en 1545, «Bibliothèque d'Humanisme et Renaissance» LXXX, 3, 2018, pp. 569-581.

1 La traduzione del De divinatione di Cicerone a opera di Robert du Souchey è un testo del 1545 a oggi pressoché sconosciuto e conservato soltanto in quattro esemplari, reperibili alla Bayerische Staatsbibliothek di Monaco, all'Università della Pennsylvania a Filadelfia, alla Kantonsbibliothek di San Gallo e alla Biblioteca Municipale di Provins. Gli studi su questo testo, iniziati grazie a Michel Simonin, a partire dal 1997, hanno permesso di ottenere informazioni più precise sulla datazione e sull'identificazione dell'editore. In particolare, la presenza di un candelabro sul frontespizio lo collegherebbe agli eredi dell'editore Pierre Gromors: infatti fino al 1544-1545 questo stampatore avrebbe utilizzato altri marchi, mentre i figli, senza dubbio meno famosi, avrebbero scelto proprio il candelabro come emblema. Si comprenderebbe così il semianonimato del volume, che invece avrebbe sicuramente avuto un successo maggiore se fosse stato pubblicato presso un editorie del calibro di Gromors padre. La dedica a Joachim de La Ferrière, condiscepolo negli studi letterari di Du Souchey è invece importante per comprendere le finalità e la tipologia del lavoro analizzato in questo studio. Viene infatti sottolineata la volontà di Souchey di offrire una traduzione con ambizioni letterarie, concepita per arricchire la lingua francese. Tuttavia, le difficoltà nella resa dell'opera ciceroniana non mancano, soprattutto a causa del lessico specialistico e dei numerosi brani in versi inseriti sia come citazioni di altri autori sia come produzioni poetiche di Cicerone stesso. Il traduttore francese sceglie di volgarizzare anche queste parti, riproducendone i versi: in questo modo, gli effetti 
retorici vengono mantenuti, pur con delle evidenti difficoltà nella resa. Nel complesso, questa De divination risulta estremamente interessante, soprattutto per la promozione della lingua francese e per l'attenzione che Du Souchey dimostra nei confronti di alcune tematiche tipiche dello scetticismo, ponendosi, ad esempio, in contrasto con la superstizione e con l'abuso della credulità religiosa e schierandosi apertamente in difesa delle tradizioni nazionali francesi. 